Drink. Water Eng. Sci. Discuss., 2, 205-229, 2009 www.drink-water-eng-sci-discuss.net/2/205/2009/ (C) Author(s) 2009. This work is distributed under the Creative Commons Attribution 3.0 License.
Drinking Water Engineering and Science

Discussions

This discussion paper is/has been under review for the journal Drinking Water Engineering and Science (DWES). Please refer to the corresponding final paper in DWES if available.

\title{
Optimized conditions for application of organic flocculant aids in water purification
}

\section{P. Polasek}

Water \& Wastewater Treatment Consulting Engineer, P.O. Box 61965, Marshalltown, 2107, South Africa

Received: 25 June 2009 - Accepted: 23 July 2009 - Published: 3 November 2009

Correspondence to: P. Polasek (polasek@mweb.co.za)

Published by Copernicus Publications on behalf of the Delft University of Technology.

Optimized conditions for organic flocculant aids in water purification

P. Polasek

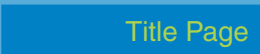

Abstract Introduction

Conclusions

Tables References Figures

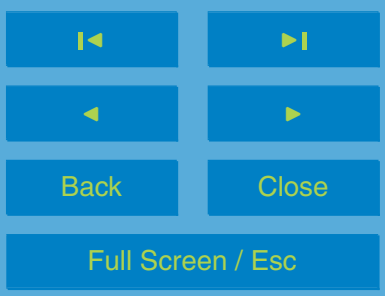

Printer-friendly Version

Interactive Discussion

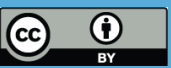




\section{Abstract}

The application of organic flocculant aid (OFA) to a system undergoing aggregation has a direct effect on the quality of purified water as well as the settleability of resultant agglomerates. The optimum conditions for OFA application exist when the formation of

5 aggregates by means of destabilisation (aggregation - CPE) reagent reaches flocculation optimum, i.e. the measure of flocculation $\gamma=1$, prior to OFA addition. Such method of OFA application is called the Post-Orthokinetic Agglomeration (POA) process. The $P O A$ process results in the formation of the fastest settleable agglomerates and the best quality of purified water matching that attainable without the use of OFA. Recirculation of the sludge conditioned by OFA back to the process of particle aggregation was found undesirable as it adversely affects the purified water quality as well as the settleability of produced agglomerates.

\section{Introduction}

There are a number of different kinds of organic flocculants (OF) each with different properties. Generally, OF is used to accelerate water clarification process and to economise operation of waterworks. The OF used in water purification can be classified according to its origin, the state in which it is dissolved in water and its applicability as shown in Table 1. Based on its applicability OF is referred to as either cationic polymer/polyelectrolyte (CPE) or organic flocculant aid (OFA). This paper deals with application of OFA only.

The OFA are used in the purification of water for their dominant adhesion properties facilitating the formation of very large and rapidly settleable agglomerates of high strength and resistance to fragmentation. The formation of such agglomerates is the pre-requisite for effective acceleration of the gravity separation processes.

25 It is a common knowledge that the application of OFA often results in poorer quality of purified water than that obtained without it and inefficient filter backwashing. Currently,
2, 205-229, 2009

Optimized conditions

for organic flocculant aids in water purification

P. Polasek

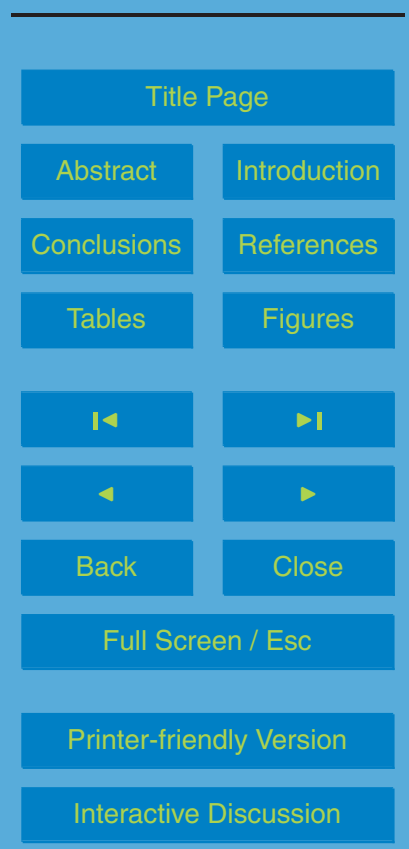


OFA is applied either together with a destabilisation reagent (coagulant), or shortly thereafter into the system undergoing aggregation. It is well known that OFA applied under such conditions results in the formation of large flocs of improved settleability. This results in reduced quantity of floc carry-over from the clarifiers/sedimentation 5 tanks which is evident by lower total residual turbidity. However, the true quality of the purified water is often poorer than that to which it is purifiable without OFA. This is the result of a greater quantity of non-separable particles of impurities remaining in the purified water, which is evident by a higher residual turbidity produced by the nonsettleable particles only. This indicates existence of certain interaction between the 10 aggregating particles of impurities and the OFA. Furthermore, the increased adhesion of the resultant flocs often results in a more rapid build-up of headloss in rapid gravity filters and their inefficient backwashing which causes operational difficulties. For these reasons the use of OFA in water purification has declined during the past two decades.

Should it be possible to eliminate the above shortcomings, the OFA would be a very 15 powerful tool capable of facilitating very significant improvement in the settleability of formed suspension, operational stability and performance efficiency of the waterworks as well as acceleration of the sedimentation process. In addition, it will have a very significant impact on the designing of new waterworks and the upgrading of existing installations. It stands to reason that different properties and behaviour characteristics of OFA in comparison to the traditional mineral flocculant aids require different conditions for their application. The conditions for the optimised application of OFA, under which the quality of the purified water is not impaired and their agglomeration capability is fully developed, are dealt with in this paper.

In the paper reference is made to the Inline High Density Suspension (IHDS) aggre25 gation process. The IHDS process takes place with a (very) high intensity agitation throughout the entire flocculation process up to the flocculation optimum is reached the flocculation optimum represents a steady state of flocculation. The IHDS process affects very favourably the properties of aggregates during the process of their formation which influence their settleability such as shape, inner structure and density. It
2, 205-229, 2009

Optimized conditions

for organic flocculant aids in water purification

P. Polasek

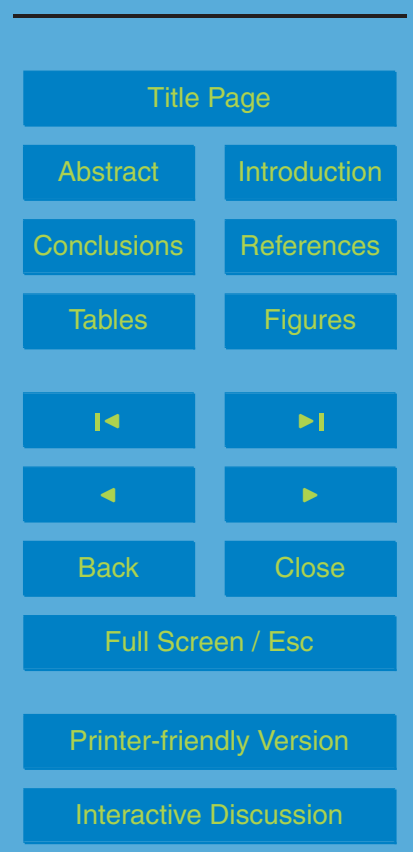


does not change the principles of formation of aggregates, i.e. the need for aggregatedestabilisation of the particles of impurities and the mechanisms of formation of the flocculent aggregates. The high intensity agitation is the inherent means increasing the compactness and hence density of formed aggregates during the process of their 5 formation without a need of applying any floc weighting substance. Hence, the IHDS process only utilizes, to the utmost benefit, the influence of high intensity agitation on the inner structure of the primary aggregates and the micro-aggregates and the resultant increase in their density process (Polasek and Mutl, 2005a, b). The IHDS process is illustrated in Fig. 2.

\section{Organic flocculant aids in water purification}

The OFA is an agglomeration agent, it is not a floc loading substance. The OFA is a high molecular weight organic substance of a molecular weight of up to 50 million. It is made up of a polymer of repeating units of a small molecular weight. Each of these repeating units carries one or more ionised groups distributed along the fibrous 15 molecule. A single OFA molecule can be imagined as a longitudinally stretched fibre with a ratio of the diameter to length reaching up to 1:1000 (Vostrcil, 1971).

\section{The OFA tested}

The only polyacrylamides, both of anionic and non-ionic character, of the Superfloc trade name suitable for drinking water application and supplied as powder, were tested.
2, 205-229, 2009

Optimized conditions

for organic flocculant

aids in water

purification

P. Polasek

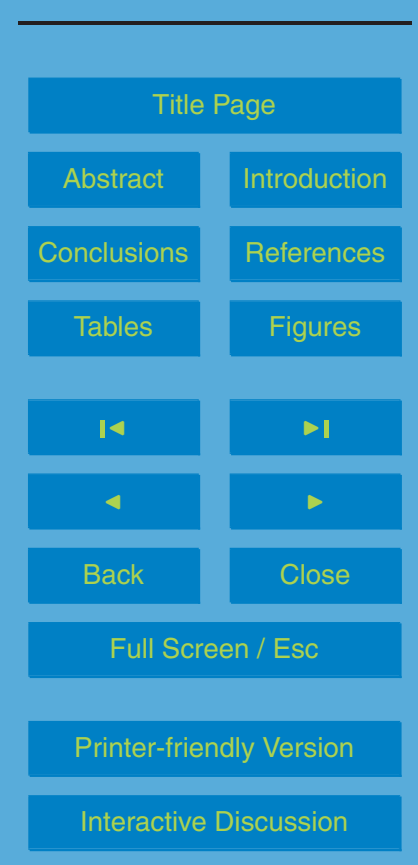




\section{The measure of flocculation}

The formation of aggregates in different waterworks takes place under different hydrodynamic conditions and usually is completed at different $\bar{G} T$ value because both $\bar{G}$ and $T$ are often influenced by the rate of flow through the waterworks. Therefore, a criterion 5 called the Measure of Flocculation $\gamma$ was developed (Polasek, 1980a). It compares the extent of particle aggregation achieved by a system with that taking place at the flocculation optimum applicable to the maximum velocity gradient $\bar{G}$ applied to the aggregation process and destabilisation reagent used. It enables to quantify the extent of the aggregation process achieved by the flocculating system in comparison to its 10 respective flocculation optimum. It is a tool for the assessment of impact of the extent of the aggregation process achieved by the system, or different systems on a mutually comparable basis, on the quality of purified water. It also permits the judging of the impact of different operational conditions on the settleability of formed aggregates and the purified water quality on a comparable basis in a waterworks or between different 15 waterworks.

The measure of flocculation $\gamma$ expresses the ratio of the extent of particle aggregation achieved by a system $\mathrm{Ca}_{S}$ to the flocculation optimum $\mathrm{Ca}_{O}$ established for the same raw water quality, maximum $\bar{G}$ applied to the aggregation process and the destabilisation reagent or CPE used. It is calculated as follows (Polasek, 1980a):

$20 \quad \gamma=\frac{C a_{S}}{C a_{O}}=\frac{(\bar{G} T)_{S}}{(\bar{G} T)_{O}}$

When $\gamma=1$ the aggregating system operates under optimum conditions. When $\gamma \ll 1$ the system is substantially under-flocculated. This adversely affects the performance of the unit operation for separation of suspension by sedimentation and also the purified water quality. When $\gamma \gg 1$, the system is over-flocculated and operates uneconomically at unjustifiably higher power consumption but the purified water quality is not impaired.
2, 205-229, 2009

Optimized conditions

for organic flocculant aids in water purification

P. Polasek
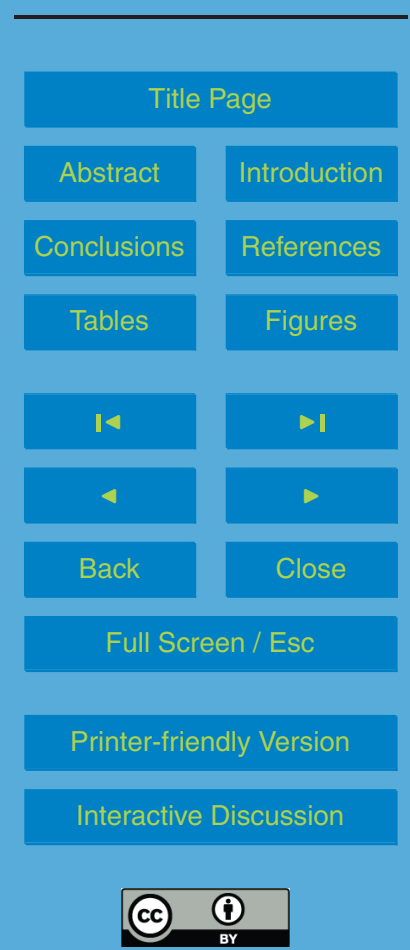


\section{Jar tests}

The purpose of jar tests study was to establish the conditions for the optimum application of OFA, i.e. to establish such conditions under which the most rapidly settleable agglomerates are formed and the purified water quality is not impaired.

The influence of the following aspects on agglomeration efficiency of various OFA was investigated:

- The significance of the value of the measure of flocculation $\gamma$ reached by the aggregating system prior to the addition of the OFA on the clarity of the purified water.

- The influence of the OFA dosage and the measure of flocculation $\gamma$ reached by the aggregating system prior to the addition of the OFA on the quality of the purified water.

- The effect of sludge recirculation on the kinetics of the aggregation process and the quality of purified water.

The jar tests were carried out with water from various surface water sources. The results obtained were very similar irrespective of water source. The quality of raw water used in the tests referred to herein is summarized in Table 2.

The jar tests were carried out using a standard Phipp \& Bird 6-station flocculator. The test took place in 2 litre standard Pyrex beakers containing 1.5 litres of water with $20 \mathrm{Al}^{3+}$ and $\mathrm{Fe}^{3+}$ salts used as destabilisation reagents or different $\mathrm{CPE}$. The aggregation process was carried out under the conditions of the IHDS process with a high rootmean-square velocity gradient $\bar{G}_{H I A}$. The OFA was added either at the beginning of agitation, or at the time of agitation corresponding to the predetermined value of the measure of flocculation $\gamma$ achieved by the aggregating system prior to OFA addition.

25 After the addition of OFA agitation of the system continued with the same root-meansquare velocity gradient $\bar{G}_{H I A}$ that was employed before the OFA addition, until the
2, 205-229, 2009

Optimized conditions

for organic flocculant aids in water purification

P. Polasek

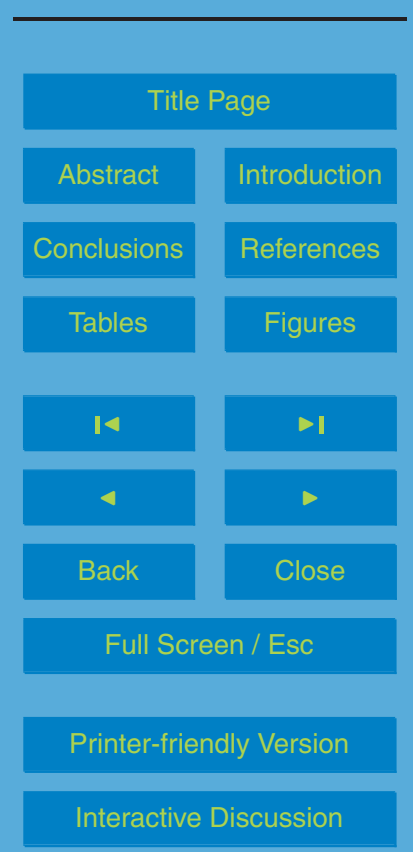

Interactive Discussion

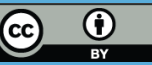


flocculation optimum $(\gamma=1)$, was reached. The last beaker was dosed with the OFA approximately $20 \mathrm{~s}$ prior to ending the aggregation process. During this $20 \mathrm{~s}$ period the flocculator speed (in all 6 stations) was increased to its maximum RPM in order to attain uniform dispersion and effective homogenisation with water of OFA added to the 5 last beaker. Then, the stirrer speed was reduced and water in all beakers was gently agitated at a speed corresponding to $\bar{G}_{L / A}=10 \mathrm{~s}^{-1}$ usually for a period of $4 \mathrm{~min}$ in order to enable the agglomerates to develop fully. The flocculator was then switched-off and the stirrers lifted from the beakers. The aggregation time was measured between the flocculator being switched-on and the addition of OFA. The sedimentation time was 10 measured from the moment the flocculator was switched-off and the stirrers removed from the beakers.

The samples of the purified water were taken at approximately $30 \mathrm{~mm}$ below the water surface. The samples were taken after 1, 3, 5, 10 and 30 min of sedimentation. The pipetting of all samples was usually completed within $15 \mathrm{~s}$.

\section{Methods}

The effect of intensity and duration of agitation on the development and properties of aggregates formed was investigated by jar test studies carried out in beakers and the results obtained were verified in full size plants. The jar tests were carried out with aluminium sulphate, ferric chloride and cationic polymer such Floccotan and Superfloc SF-577 under optimised reaction conditions.

The effect of conditions of agitation on the properties of aggregates formed and their settleability was evaluated by changes in the content of anion of added coagulant $(M e)$ and turbidity $(T u)$ - affix $F$ means that all separable particles were removed and only non-separable particles remain in the analysed sample. Turbidity was mea-

sured by photometers and Me photo-colorimetrically. The aggregate-size distribution of the formed aggregates was measured by the test of aggregation and the removal of impurities by the attained and attainable separation efficiency (Hereit et al., 1980).
2, 205-229, 2009

Optimized conditions

for organic flocculant aids in water purification

P. Polasek

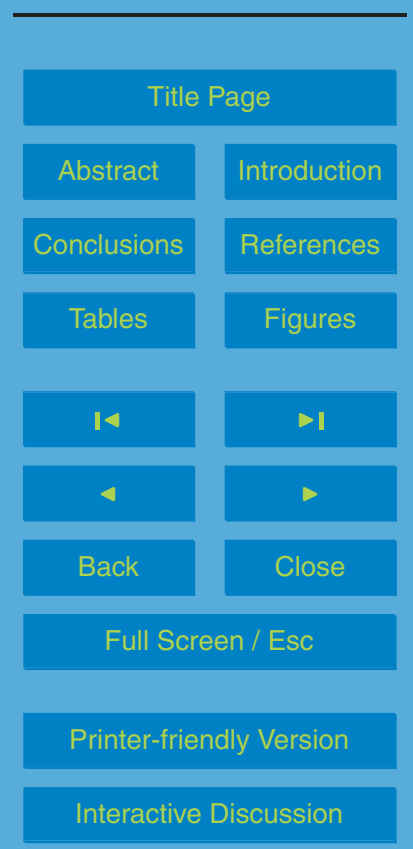


The non-separable are those particles that are kept in suspension by means of their aggregate stability. These particles are usually of analytical and colloidal degree of dispersity. The non-separable particles remaining in the purified water are the nondestabilised, partly destabilised but not aggregated particles and the particles of desta5 bilisation agent. From the point of view of total water purification process efficiency the quantity of non-separable particles determines the attainable efficiency of water purification process.

The OFA interaction with the aggregation process and its influence on the purified water quality was evaluated by comparing residual values of both turbidity and cation 10 of the destabilisation reagent $(\mathrm{Me})$ with that of the blind (without OFA). The application of OFA was considered to be at its optimum when both the residual turbidity and the residual $\mathrm{Me}$ of the destabilisation reagent did not exceed the values obtained from the blind after 30 min sedimentation.

The pattern of results obtained based on turbidity and Me were very similar and 15 therefore only the results based on turbidity measurements are included in this paper.

\section{Results and discussion}

\section{The Post-Orthokinetic Agglomeration process}

The typical results obtained from jar tests are shown in Fig. $1\left(G^{*}\right.$ stands for $\left.\bar{G}\right)$. The comparison of the individual curves in Fig. 1 shows considerable differences between 20 residual turbidity of individual tests measured after $10 \mathrm{~min}$ sedimentation. These differences are inversely proportional to the $\gamma$ value attained by the system prior to the addition of OFA and remained unchanged after 30 and $60 \mathrm{~min}$ of sedimentation. Therefore, the turbidity reading after $10 \mathrm{~min}$ sedimentation is considered proportional to the quantity of non-settleable particles remaining in the purified water and reflecting the 25 dent from Fig. 1 the quantity of non-settloable particles remaining in the purified water
2, 205-229, 2009

Optimized conditions

for organic flocculant aids in water purification

P. Polasek

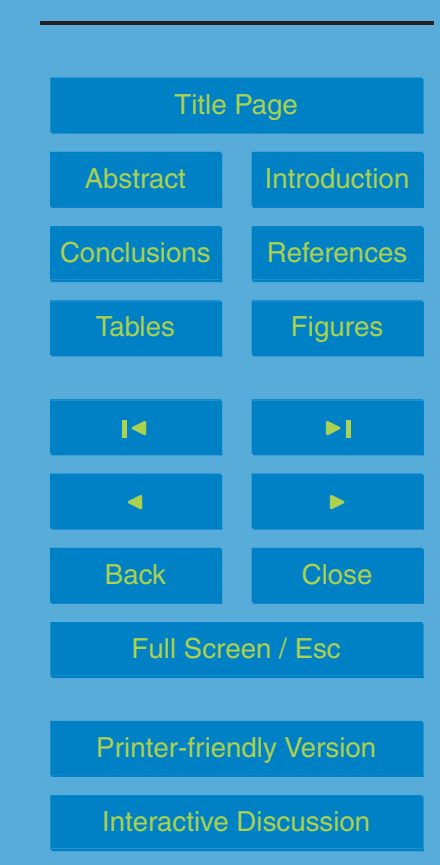

Interactive Discussion

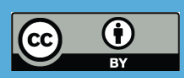


decreased with increasing $\gamma$ value attained by the aggregating system prior to OFA addition. The purified water clarity which was the same as that produced by the blind was achieved only when OFA was added into the system at its flocculation optimum $(\gamma=1)$.

5 Comparison of the individual curves at the beginning of sedimentation in Fig. 1 shows considerable improvement in the kinetics of sedimentation of the agglomerates formed with OFA added at higher $\gamma$ value in comparison to that of the blind. At the same time, it shows that the clarity impairment of the purified water decreases with an increasing $\gamma$-value attained by the system prior to OFA addition and disappears completely when OFA is added at the flocculation optimum $(\gamma=1)$.

The significance of different $\gamma$-values attained prior to OFA addition for increasing sedimentation velocity of the formed agglomerates is evident from comparison of a difference in residual turbidity measured after 1 and $10 \mathrm{~min}$ of sedimentation (Fig. 1). The differences read as follows:

\begin{tabular}{llllll} 
Measure of Flocculation $\gamma$ & 0 & 0.25 & 0.5 & 0.75 & 1 \\
\hline Difference in Residual Turbidity & 4.4 & 2.75 & 1.75 & 0.9 & 0.8
\end{tabular}

The highest difference in residual turbidity means the lowest sedimentation velocity of the resultants agglomerates is attained and this occurs when the OFA is applied together with the destabilisation reagent. In contrast, the lowest difference in residual turbidity means the highest sedimentation velocity of the resultant agglomerates is attained and this occurs when the OFA is applied at about the flocculation optimum $(\gamma=1)$. The difference between the two is more than 5 -fold. The comparison of the difference between the residual turbidity of the blind (no OFA added) with that of the lowest turbidity (the highest sedimentation velocity) is about 30 -fold. It stands to reason that these differences correspond to the same differences in sedimentation velocities and indicate potential for speeding up sedimentation process.

This can be explained by the character of OFA. OFA is a strong hydrophilic colloid.
2, 205-229, 2009

\section{Optimized conditions}

for organic flocculant aids in water purification

P. Polasek

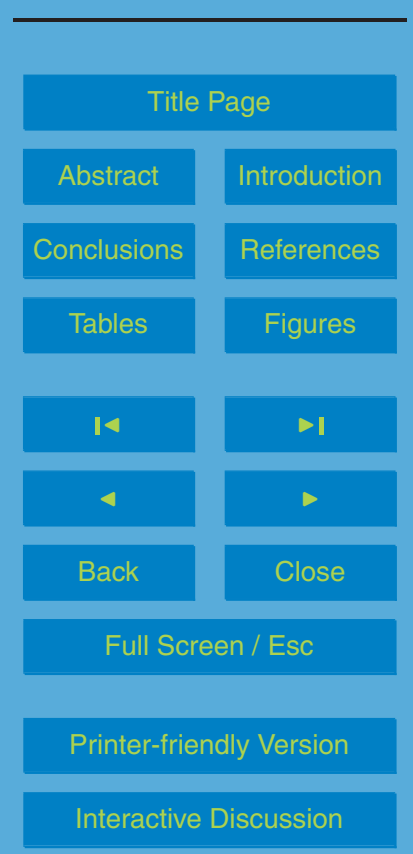


When added to the aggregating system, OFA produces a protective colloid which restabilizes the partly destabilised particles as well as the destabilised particles but not yet aggregated and the particles aggregated to the lowest order. Furthermore, it also prevents aggregation of these particles to proceed quantitatively and thereby rendering the 5 process less efficient. This effect is more intense with higher OFA dosage when the greater quantity of non-aggregated particles and the particles aggregated to the lowest order exist in the system prior to the addition of OFA. Such a situation exists at the beginning of the aggregation process and is most intense when both the destabilisation reagent and the OFA are added next to each other. With progressing aggregation 10 the quantity of non-aggregated particles and those aggregated to the lowest order decreases. Therefore the susceptibility of the aggregating system to the influence of the lyophilic character of the OFA gradually diminishes and disappears completely when the aggregation process is brought to its flocculation optimum prior to the addition of OFA. When added to the system in which aggregation was completed at $\bar{G} T>$ floccu15 lation optimum $(\gamma>1)$, OFA has no effect on the final clarity of the purified water.

Furthermore, the lower sedimentation velocity attained when agglomerates are formed at $\gamma \ll 1$ is also facilitated by two factors, namely:

1. The prolonged OFA exposure to a high $\bar{G}_{\text {HIA }}$ used during the IHDS process resulting in more intensive shearing of the polymer chains and hence formation of smaller agglomerates.

2. The prolonged OFA interaction with the aggregation process results in less compact (dense) agglomerates.

In addition, it was established that smaller size of the micro-aggregates formed by the IHDS process do not affect the formation of very large and rapidly settleable agglom25

erates formed by the POA process. In fact, the IHDS formed dense micro-aggregates positively influence sedimentation velocity of the resultant agglomerates. Therefore, the IHDS process can proceed with the highest $\bar{G}$, thus reducing the period of the aggregation process.

2, 205-229, 2009

Optimized conditions

for organic flocculant aids in water purification

P. Polasek

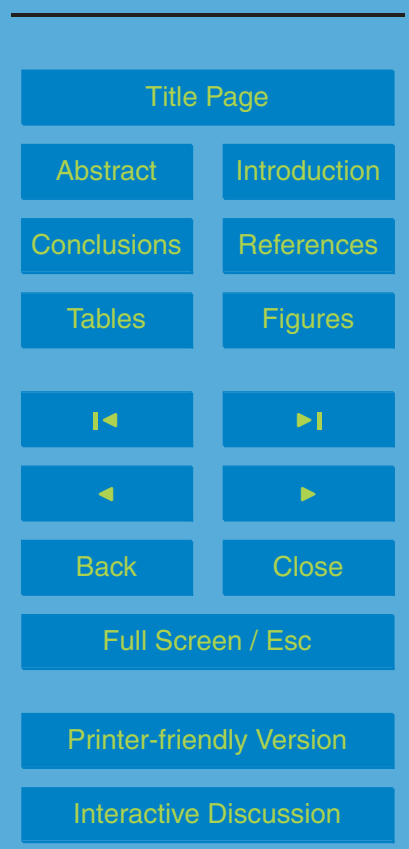

Interactive Discussion

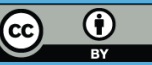


The process of agglomeration when the OFA is applied at about the flocculation optimum is called the Post-Orthokinetic Agglomeration (POA) process (Polasek and Mutl, 2005a, b). The POA process represents the optimised method for OFA application. It is the process of agglomeration whereby the aggregates formed by means 5 of destabilisation reagent or CPE (preferably by the IHDS process) are the building units bridged together by means of an OFA into large and very rapidly settleable agglomerates. The POA in combination with the IHDS process constitute the High Rate Clarification (HRC) technology. The HRC technology is illustrated in Fig. 2. This process is capable of considerable acceleration of the clarification process as is evident

10 from the results of operation of HR clarifiers some of which are introduced in Table 3 (Polasek, 1980b).

The POA method fully utilises the benefits of a high density of micro-aggregates formed by the IHDS process for the formation of heavy and very settleable agglomerates, as Fig. 4 shows. The resultant agglomerates formed with a very small dosage of 15 OFA (in this particular instance at a dosage of $D=0.05 \mathrm{mg} \mathrm{l}^{-1}$ ) were so large and heavy that they were already settling during the agglomeration agitation (Fig. 4a).

It was further observed that the POA process together with the OFA dosage influence the size and adhesion properties of the agglomerates formed as is evident from the changes of sediment distribution at the bottom of the beakers. By increasing dosage of OFA, the character of sludge changes and its compactness increases as is evident from Fig. 4c.

\section{The influence of OFA dosage on the size of formed agglomerates and the purified water}

The jar tests were carried out to establish the influence of OFA dosage on the im25 pairment of the aggregation process. Different OFA were tested at different dosages applied to the system aggregating under different $\bar{G}$ and $\bar{G} T$ values. The results obtained from all these tests were very similar. The typical results obtained after $30 \mathrm{~min}$ of sedimentation with two different dosages of the same OFA are illustrated in Fig. 3.
2, 205-229, 2009

Optimized conditions

for organic flocculant aids in water purification

P. Polasek
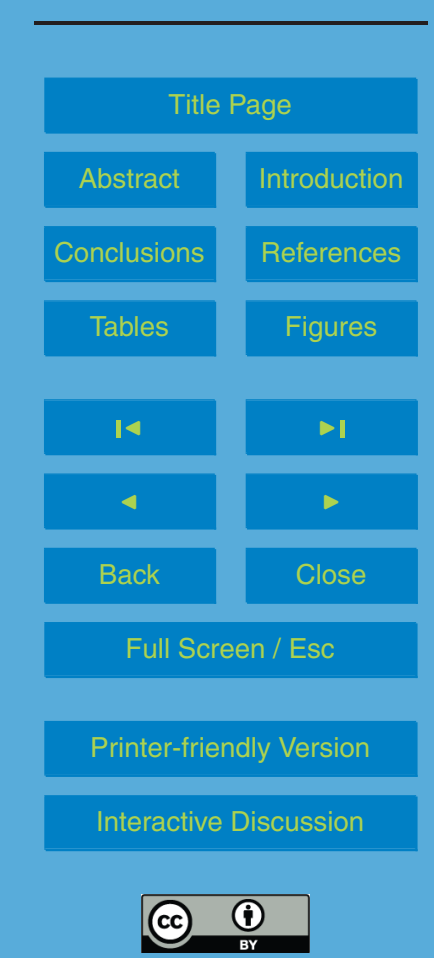
Figure 3 shows that in addition to the measure of flocculation $\gamma$ attained by the system prior to the addition of OFA the impairment of purified water clarity is also directly proportional to the dosage of the OFA applied. The lower the $\gamma$ value and the higher the OFA dosage, the greater is the impairment of the aggregation process and 5 the poorer is the clarity of the purified water.

Furthermore, the jar tests also showed that under the POA process the size of the resultant agglomerates and thereby their sedimentation velocity can be controlled by OFA dosage as it is evident from Fig. 4b. The OFA dosage required to achieve the same agglomeration effect is quantity of suspension dependent.

\section{Sludge recirculation}

The influence of sludge recirculation on the velocity of water purification process and the clarity of the purified water was also investigated.

The water purification technology used in these test is the decarbonisation by cold lime precipitation reactions using activated silica as the flocculant aid. The potential of

OFA for the acceleration of the sedimentation process was investigated by replacing activated silica with OFA and comparing the residual turbidity attained. This investigation was carried out in two series of tests, each series consisting of two jar tests. The sludge produced by the first jar tests of each of the series of tests was used to inoculate the raw water in the second series of jar tests. The jar tests were carried 20 out with the same $\bar{G}_{H I A}=100 \mathrm{~s}^{-1}$ applied over different agitation times producing different $\bar{G} T$ values. The OFA used was applied when the predetermined $\bar{G} T$ value was reached. In all these tests, with and without OFA, the high intensity of aggregation agitation $\left(\bar{G}_{H I A}=100 \mathrm{~s}^{-1}\right)$ was always followed by the low intensity agglomeration agitation with a $\bar{G}_{L / A}=10 \mathrm{~s}^{-1}$ for a period of $4 \mathrm{~min}$. Residual turbidity was measured after $10 \mathrm{~min}$
2, 205-229, 2009

Optimized conditions

for organic flocculant aids in water

purification

P. Polasek

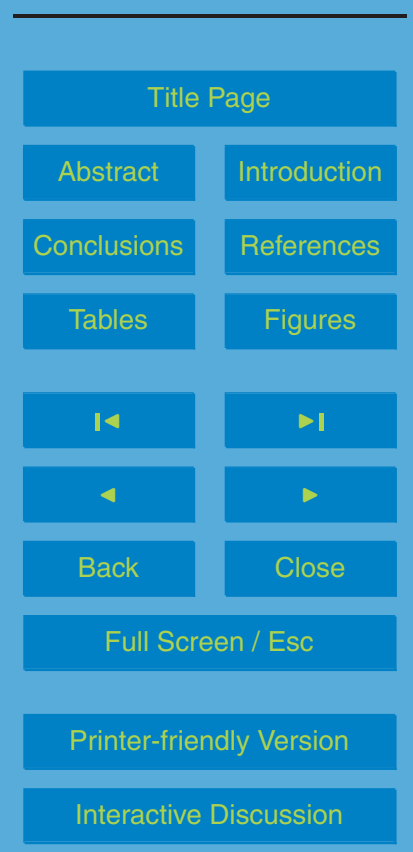


The first series of the jar tests was carried out with activated silica. The results obtained are illustrated by curves 1 and 2 in Fig. 5 . In the first jar tests (curve 1) the raw water was purified with $2.0 \mathrm{mgl}^{-1}$ of activated silica and $80 \mathrm{mgl}^{-1}$ of lime. The formed suspension settled for a period of $60 \mathrm{~min}$. The water was then decanted from 5 the beaker and the sediment retained. This beaker was then filled with fresh raw water. The inoculated raw water was then dosed with $2.0 \mathrm{mg} \mathrm{I}^{-1}$ of activated silica and $80 \mathrm{mgl}^{-1}$ of lime and subjected to the same conditions of agitation as in the previous test. The results obtained are illustrated in curve 2. From the comparison of both curves it is evident that sludge recirculation accelerates considerably both the process 10 of floc formation by providing crystallisation nuclei as well as the kinetics of sedimentation of the formed suspension.

The effect of the OFA was tested in the second series of jar tests. These jar tests were carried out with the same raw water as the first series of jar tests. The only difference was that SF-A110 replaced activated silica and it was applied under the 15 conditions of the POA process. SF-A110 was dosed at a rate of $0.1 \mathrm{mgl}^{-1}$ and flash mixed for a period of $20 \mathrm{~s}$. The results obtained are illustrated by curves 3 and 4 (Fig. 5). It follows from comparison of these two curves that when the suspension conditioned by OFA is recirculated the protective colloid produced by the OFA hinders the aggregation process. This is evident by the poorer clarity of the purified water 20 produced.

Comparison of both series of tests shows that when the OFA was applied into the system without sludge recirculation the application of the OFA facilitated the formation of fast settling agglomerates and improved the kinetics of sedimentation of the resultant suspension more efficiently than activated silica (curves 1 and 3 in Fig. 5). When sludge recirculation was applied, the formation and settleability of the resultant suspension formed with activated silica was found to be incomparably faster and the purified water clarity better than that obtained with the OFA (curves 2 and 4 in Fig. 5). Evidently, recirculation of the sludge conditioned with OFA is undesirable.
2, 205-229, 2009

Optimized conditions

for organic flocculant aids in water purification

P. Polasek

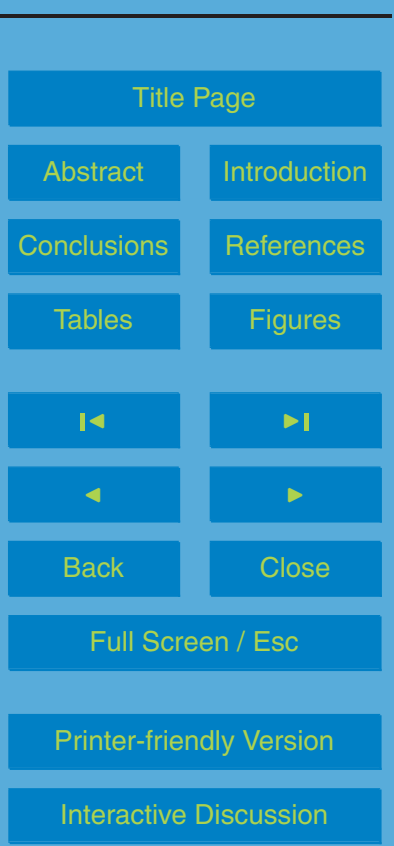




\section{The influence of OFA on the dosage of destabilisation reagent}

It is believed by some that the use of OFA results in a reduction of the operational dosage of destabilisation reagent. This is a fallacy perhaps originating from the visual observations of the clarity of water at the outlet from clarifiers which often appears im5 proved when OFA is applied. This improvement is the result of the reduced quantity of suspension carry-over from the clarifier owing to the agglomeration of even the smallest micro-aggregates and hence the improved operational stability of the clarifier. The actual clarity of the purified water could be worse however due to a greater quantity of non-separable particles remaining in the purified water eventhough the clarity of settled 10 water appears to have improved.

\section{Acceleration of the water purification process}

The important contribution of OFA for the acceleration of the water purification process is evident from comparison of performance results of the different clarifier types in Table 3, namely Clariflocculator, Pretreator and HR Clarifier installed at the Old Waterworks of the Bethlehem Municipality and purifying the same raw water to approximately the same clarity. The Clariflocculator is a radial flow type sedimentation tank. The Pretreator is a radial flow sludge blanket type clarifier combining radial and vertical flow in the sludge blanket. The HR clarifier a vertical flow type clarifier with a fully fluidised sludge blanket incorporating the HRC technology - it is capable of operating at an upflow velocity well above $25 \mathrm{~m} \mathrm{~h}^{-1}$ (Polasek, 1980b; Polasek and Mutl, 2005a).

The Clariflocculator was operated at an upflow velocity of $1.2 \mathrm{~m} \mathrm{~h}^{-1}$ and total retention time of about $4 \mathrm{~h}$. The Pretreator was operated at an upflow velocity of about $1.5 \mathrm{~m} \mathrm{~h}^{-1}$ and total retention time of about $3.5 \mathrm{~h}$. The HR clarifier was operated at an upflow velocity of $15.5 \mathrm{~m} \mathrm{~h}^{-1}$, total retention time of about $40 \mathrm{~min}$. While the residual turbidity at the outlet from all these clarifiers were very similar (around $7 \mathrm{NTU}$ ), the optimised aluminium sulphate dosage applied to the HR clarifier was about $15 \%$ lower due
2, 205-229, 2009

Optimized conditions for organic flocculant aids in water purification

P. Polasek

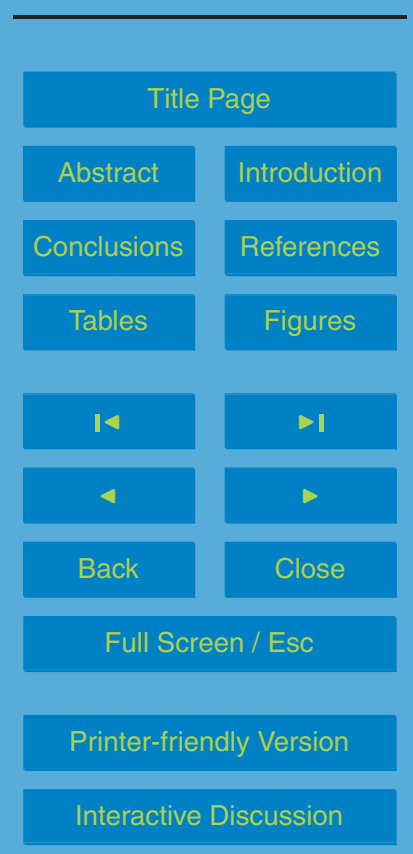


to effective agitation than that required by the Clariflocculator and Pretreator to produce same clarity purified water. In addition, the lowest residual turbidity produced by the non-separable particles only (all separable particles were removed from tested samples by centrifugation) measured at the outlet from the HR clarifier was $C_{C} F=1.2 \mathrm{NTU}$ 5 and from the Pretreator $C_{C} F=1.4$ NTU. The performance efficiency of the Clariflocculator was considerably poorer, $C_{C} F=2.7 \mathrm{NTU}$. While the attained separation efficiency $\varphi$ for all three clarifiers was very similar around $\varphi=93 \%$; attainable separation efficiency $\bar{\varphi}$ differed considerably, i.e. Clariflocculator $\bar{\varphi}=96.12 \%$, Pretreator $\bar{\varphi}=97.16$ and HR Clarifier $\bar{\varphi}=98.63$. The tremendous potential of the HRC technology for the accelera10 tion of the clarification process is evident from comparison of the above results.

\section{Conclusions}

1. When OFA is added into a system undergoing aggregation its hydrophilic properties produce a protective colloid upon the non-aggregated particles and particles aggregated to the lowest order thus preventing their aggregation to proceed quantitatively and thereby rendering the process less efficient. This is evident by a higher residual content of the non-separable particles remaining in the purified water. The effect of the protective colloid gradually diminishes as aggregation progresses prior to OFA addition. The quality of purified water was found to be the same as that without the use OFA only when the aggregation process by means of a destabilisation reagent or CPE is completed prior to OFA addition. This method of OFA application is called the Post-Orthokinetic Agglomeration (POA) process. Under the POA process, the hydrophilic character of the OFA cannot impair the efficiency of the aggregation process and thereby the purified water quality.

2. The OFA application under the POA process eliminates all known shortcomings related to purified water quality and enables the agglomeration potential of OFA to be fully developed and utilised.

Optimized conditions for organic flocculant aids in water purification

P. Polasek

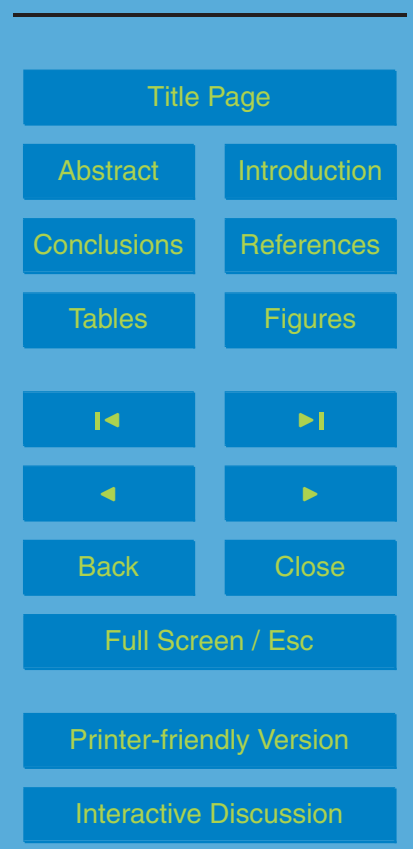


3. The size of the resultant agglomerates and thereby their sedimentation velocity is controlled by OFA dosage.

4. The POA together with the IHDS process constitute the High Rate Clarification (HRC) technology. Under the POA process the high density micro-aggregates formed by the IHDS process are the building units bridged together by means of OFA into large, heavy and very rapidly settleable agglomerates. The HRC process is an ideal tool enabling very significant acceleration of the sedimentation process and effective and inexpensive upgrading of the existing water purification works.

5. The full scale plant operation proved the capability of the High Rate Clarification process to very significantly accelerate the entire water clarification process. The HR clarifier was found capable of operating at an upflow velocity exceeding $25 \mathrm{~m} \mathrm{~h}^{-1}$ and formation of both the aggregates and the resultant agglomerates and their separation including sludge thickening is completed in this clarifier within a time shorter than $40 \mathrm{~min}$. Therefore, the use of OFA warrants revival.

6. The use of OFA does not result in reduction of dosage of the destabilisation reagent (or $\mathrm{CPE}$ ). The optimised dosage of destabilisation reagent is determined by the raw water quality, destabilisation reagent and the reaction conditions required to produce the desired quality of purified water. Operational experience with filtration of OFA formed suspension proved the necessity for the use of coarser filter media and combined air + water for backwashing.

7. Recirculation of sludge conditioned with the OFA produces poorer clarity of purified water than that obtained without OFA. The extent of such impairment is proportional to OFA dosage. Recirculation of the sludge conditioned with OFA is, therefore, undesirable.
2, 205-229, 2009

Optimized conditions

for organic flocculant aids in water

purification

P. Polasek

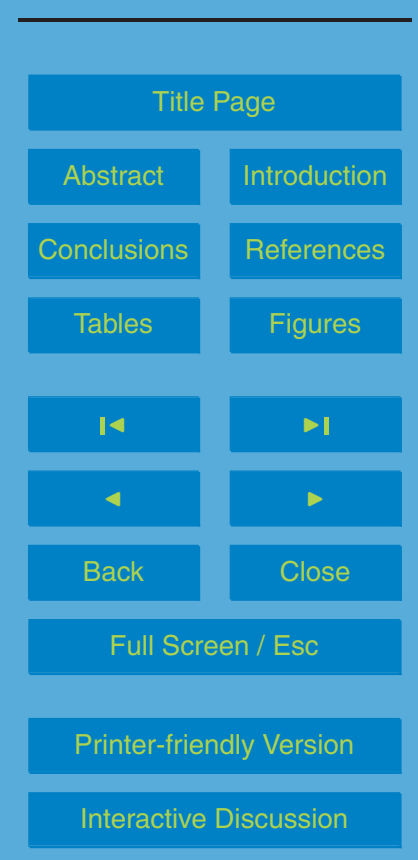




\section{References}

Hereit, F., Mutl., S., and Vagner, V.: The formation of separable suspension and the methods its assessment, J. Aqua, 29, 95-99, 1980.

Polasek, P.: Methods and testing procedures for monitoring and evaluating waterworks performance, Proc. Int. Conf., Johannesburg, 1980a.

Polasek, P.: HR clarifier performance results, Proc. Int. Conf., Johannesburg, 1980b.

Polasek, P. and Mutl, S.: Acceleration of gravity separation process, J. Filtration, 5(1), 33-39, 2005a.

Polasek, P. and Mutl, S.: High Rate Clarification Technology, Proc. IWA Spec. Conf., Particle Separation 2005, Seoul, South Korea, 2005b.

Vostrcil, J.: The effect of organic flocculants on water treatment and decontamination of water by a floc blanket, VUV Praha, Prace a Studie No. 129, 1971.

2, 205-229, 2009

Optimized conditions for organic flocculant aids in water purification

P. Polasek

Title Page

Abstract

Conclusions

Tables

14

$<$

Back

Back

Full Screen / Esc

Printer-friendly Version

Interactive Discussion 
2, 205-229, 2009

Optimized conditions for organic flocculant aids in water

Table 1. Classification of organic flocculants.

\begin{tabular}{|c|c|c|c|c|c|}
\hline \multicolumn{2}{|c|}{ ORIGIN } & \multicolumn{2}{|c|}{ CHEMICAL CHARACTERISTIC } & \multicolumn{2}{|c|}{ APPLICATION } \\
\hline \multirow{2}{*}{$\begin{array}{l}\text { NATURAL } \\
\text { POLYMRS }\end{array}$} & $\begin{array}{c}\text { CHEMICALLY } \\
\text { TREATED }\end{array}$ & \multirow{4}{*}{ POLYELECTROLYTES } & CATIONIC & $\begin{array}{l}\text { PURIFICATION } \\
\text { AGENT } \\
\text { (CPE) }\end{array}$ & \multirow{5}{*}{$\begin{array}{l}\text { FILTRATION } \\
\text { AID } \\
\text { (OFiA) }\end{array}$} \\
\hline & $\begin{array}{l}\text { CHEMICALLY } \\
\text { UNTREATED }\end{array}$ & & ANIONIC & \multirow{4}{*}{$\begin{array}{l}\text { FLOCULATION } \\
\text { AID } \\
\text { (OFA) }\end{array}$} & \\
\hline \multirow{3}{*}{\multicolumn{2}{|c|}{ SYNTHETIC POLYMERS }} & & AMPHOLYTE & & \\
\hline & & & MIXED & & \\
\hline & & NONELECTROLYTES & NON-IONIC & & \\
\hline
\end{tabular}

\section{purification}

P. Polasek

Title Page

\section{Abstract}

Conclusions

Tables

14

4

Back
Introduction

References

Figures

-1

$>$

Close
Full Screen / Esc

Printer-friendly Version

Interactive Discussion 
Table 2. The average quality of different raw waters used in the study.

\begin{tabular}{llccc}
\hline Determinant & Units & Vaal Dam & Loch Athlone Dam & Saulspoort Dam \\
\hline Temperature & ${ }^{\circ} \mathrm{C}$ & 18 & $12-25$ & $12-25$ \\
$\mathrm{pH}$ & - & 8.2 & 7.7 & $7.4-8.2$ \\
Turbidity & $\mathrm{NTU}$ & 160 & $50-690$ & $30-250$ \\
Colour & $\mathrm{mg} \mathrm{Pt}^{-1}$ & 17.5 & $5-15$ & $10-40$ \\
Total Hardness & $\mathrm{mg} \mathrm{CaCO}_{3} \ell^{-1}$ & 71 & 108 & $90-160$ \\
Total alkalinity & $\mathrm{mg} \mathrm{CaCO}_{3} \ell^{-1}$ & 65 & 75 & $75-140$ \\
$\mathrm{COD}_{\mathrm{Mn}}$ & $\mathrm{mg} \mathrm{O}_{2} \ell^{-1}$ & 4.2 & 3.4 & 6.5 \\
THM - potential value & $\mu \mathrm{g} \mathrm{CHCl}_{3} \ell^{-1}$ & - & - & 878 \\
\hline
\end{tabular}

Optimized conditions for organic flocculant aids in water purification

P. Polasek 
Table 3. Comparison of performance of different type clarifiers.

Raw water:

Raw water turbidity:

Destabilisation reagent:

Optimum dosage - Tu removal:

\begin{tabular}{|c|c|c|c|c|c|c|c|c|c|c|c|}
\hline \multirow[b]{2}{*}{ Type of clarifier } & \multirow[b]{2}{*}{$\begin{array}{l}\text { Point of } \\
\text { measurement }\end{array}$} & \multirow[b]{2}{*}{$\begin{array}{l}\text { Measure of } \\
\text { flocculation } \\
y \\
{[-]}\end{array}$} & \multirow[b]{2}{*}{$\begin{array}{l}\text { Upflow velocity } \\
\text { at sludge } \\
\text { blanket level } \\
{[\mathrm{m} / \mathrm{h}]}\end{array}$} & \multicolumn{2}{|c|}{ Dosing rate } & \multicolumn{2}{|c|}{ Turbidity } & \multicolumn{4}{|c|}{ Aggregate size-fractions } \\
\hline & & & & $\begin{array}{l}\mathrm{Al}_{2}\left(\mathrm{SO}_{4}\right)_{3} \\
{[\mathrm{mg} / \mathrm{l}]}\end{array}$ & $\begin{array}{l}\text { SF-A110** } \\
{[\mathrm{mg} / \mathrm{l}]}\end{array}$ & [NTU] & [NTU] & $M A$ & [\%] & $P R$ & $N A$ \\
\hline Pretreator & $\begin{array}{l}\text { Flocculation chamber outlet } \\
\text { Hydraulic jump } \\
\text { Clarifier outlet } \\
\text { Filtrate }\end{array}$ & $\begin{array}{l}0.56 \\
0,66\end{array}$ & 1.5 & 60 & 0 & $\begin{array}{l}102 \\
102 \\
7.1 \\
0.50\end{array}$ & $\begin{array}{l}4.9 \\
4.0 \\
1.5 \\
0.32\end{array}$ & $\begin{array}{l}75.5 \\
17.6 \\
1.5 \\
0.0\end{array}$ & $\begin{array}{l}14.7 \\
57.9 \\
2.5 \\
0.0\end{array}$ & $\begin{array}{l}6.2 \\
22.3 \\
1.6 \\
0.18\end{array}$ & $\begin{array}{l}3.6 \\
2.2 \\
1.4 \\
0.32\end{array}$ \\
\hline Clariflocculator & $\begin{array}{l}\text { Flocculation chamber outlet } \\
\text { Clarifier outlet } \\
\text { Filtrate* }^{\star}\end{array}$ & 0.56 & 1.2 & 60 & 0 & $\begin{array}{l}102 \\
7.2 \\
0.71\end{array}$ & $\begin{array}{l}4.9 \\
2.9 \\
0.53\end{array}$ & $\begin{array}{l}75.5 \\
1.2 \\
0.0\end{array}$ & $\begin{array}{l}14.7 \\
1.9 \\
0.0\end{array}$ & $\begin{array}{l}6.2 \\
1.4 \\
0.18\end{array}$ & $\begin{array}{l}3.6 \\
2.7 \\
0.53\end{array}$ \\
\hline HR Clarifier & $\begin{array}{l}\text { Flocculation chamber outlet } \\
\text { Clarifier outlet } \\
\text { Filtrate* }^{*}\end{array}$ & 0.99 & 15.5 & 52 & 0.172 & $\begin{array}{l}102 \\
7.0 \\
0.71\end{array}$ & $\begin{array}{l}1.7 \\
1.4 \\
0.53\end{array}$ & $\begin{array}{l}50 \\
2.6 \\
0.0\end{array}$ & $\begin{array}{l}32.6 \\
1.9 \\
0.0\end{array}$ & $\begin{array}{l}16.1 \\
1.4 \\
0.18\end{array}$ & $\begin{array}{l}1.3 \\
1.2 \\
0.53\end{array}$ \\
\hline
\end{tabular}

* Clariflocculator and HR clarifier outlets combined prior to filtration

** SF-A110 dissolved in plain tap water
Mixture of Saulspoort Dam and Loch Athlone Dam waters

$\mathrm{C}_{0}=102 \mathrm{NTU}$

$\mathrm{C}_{0} \mathrm{~F}=54 \mathrm{NTU}$

Aluminium sulphate

$M A$ - macro-aggregates

$M I$ - micro-aggregates

$P R$ - primary-aggregates

$N A$ - non-aggregated/nonseparable particles

$52 \mathrm{mg} /$
Optimized conditions for organic flocculant aids in water purification

P. Polasek

Title Page

\section{Abstract}

Introduction

Conclusions

References

Tables

Figures

14

$>1$

4

Back

Full Screen / Esc

Printer-friendly Version

Interactive Discussion 


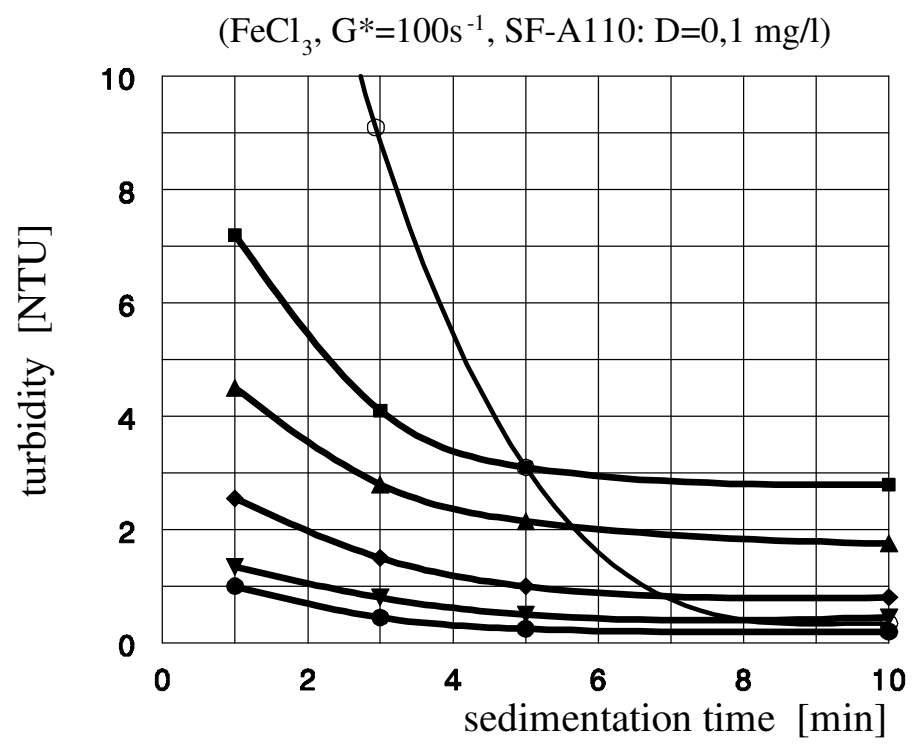

Fig. 1. Significance of $\gamma$ value reached prior to OFA addition on the quality of purified water.
2, 205-229, 2009

Optimized conditions for organic flocculant aids in water purification

P. Polasek

Title Page

\section{Abstract}

Conclusions

- $1.0 \gamma$
Tables

14

4

Back
Introduction

References

Figures

DI
Full Screen / Esc

Printer-friendly Version

Interactive Discussion 

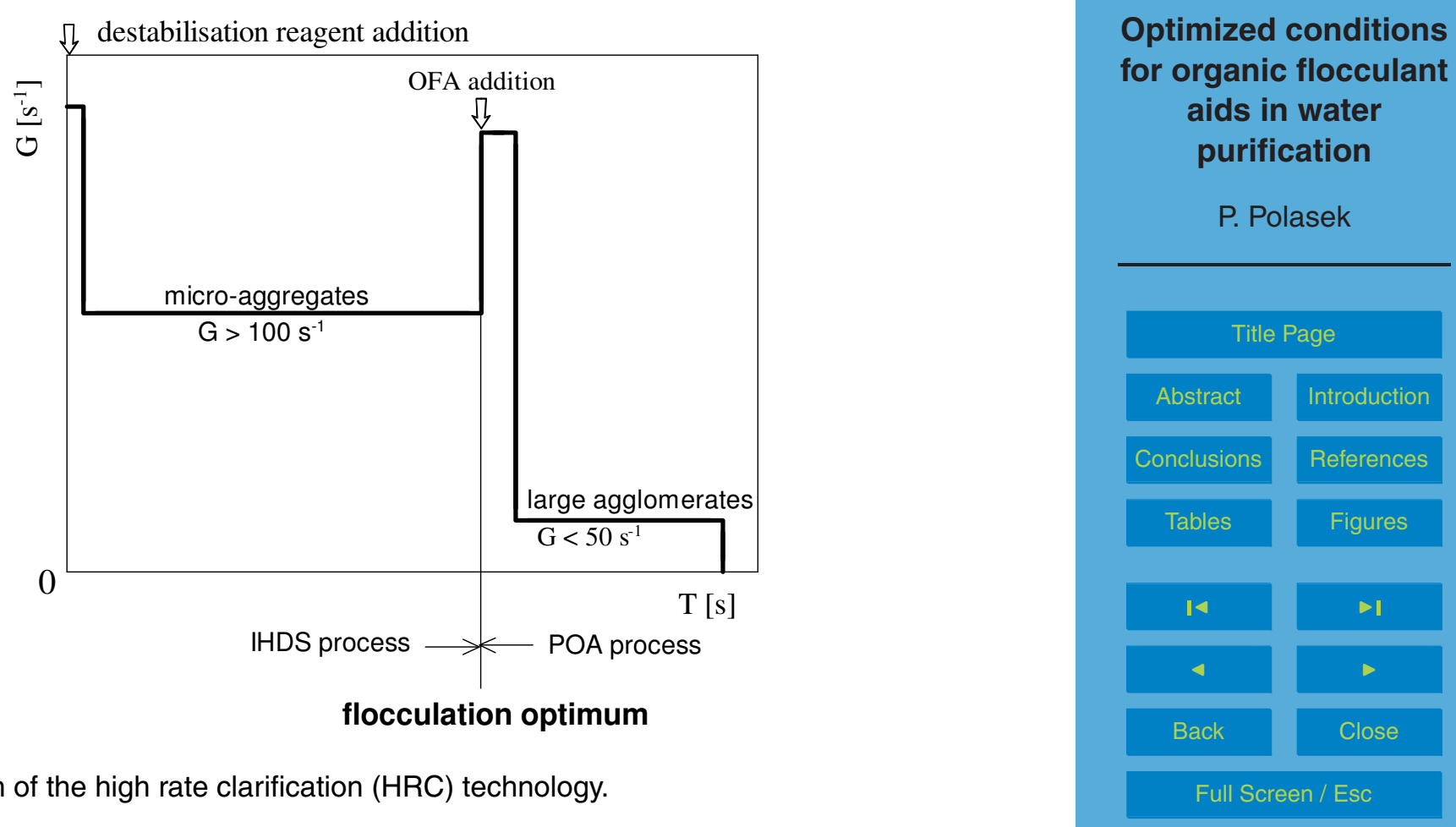

Fig. 2. Illustration of the high rate clarification (HRC) technology. 


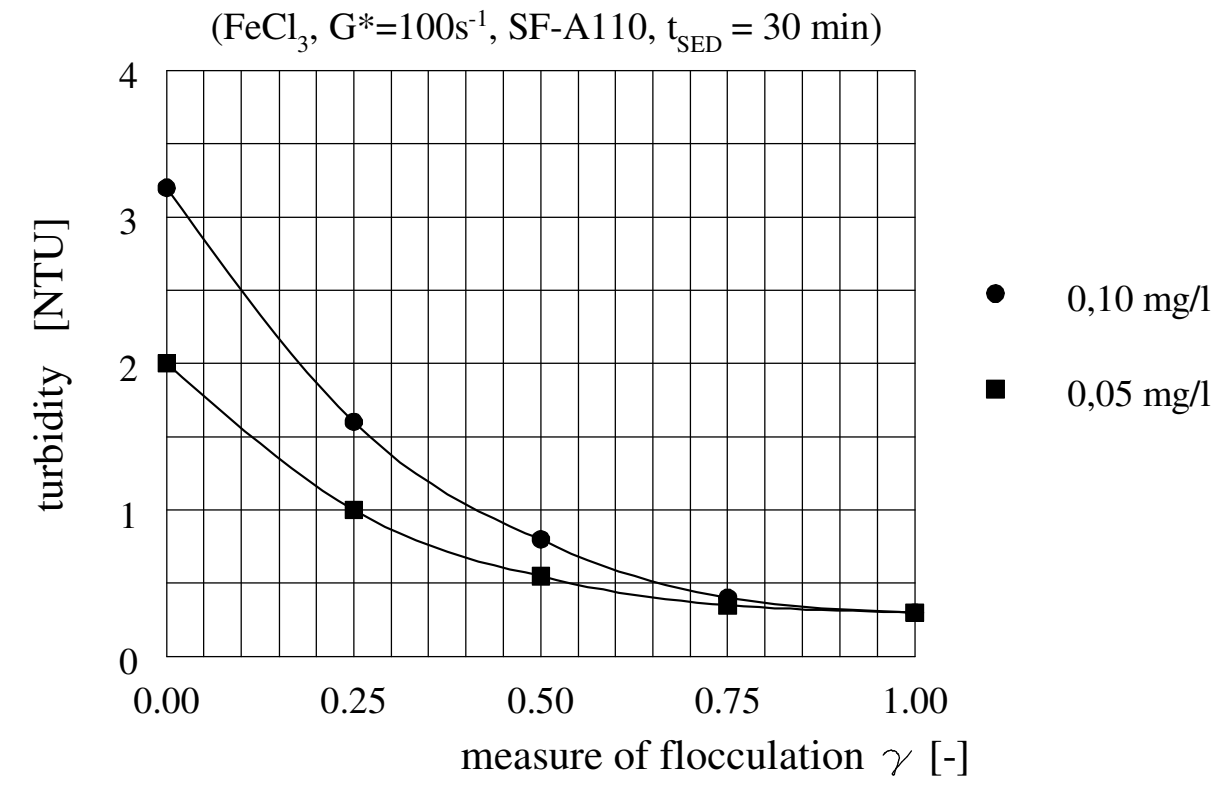

Fig. 3. Influence of OFA dosage and $\gamma$ reached prior to OFA addition on the quality of purified water.

2, 205-229, 2009

\section{Optimized conditions} for organic flocculant aids in water purification

P. Polasek

\section{Title Page}

Abstract

Conclusions

Tables

14

14

4

Back
Introduction

References

\section{Figures}

$\rightarrow$

$>$

Close

Full Screen / Esc

Printer-friendly Version

Interactive Discussion 


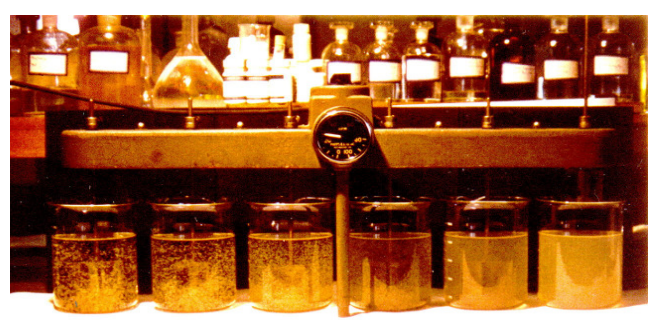

(a)

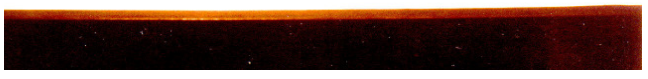

(b)
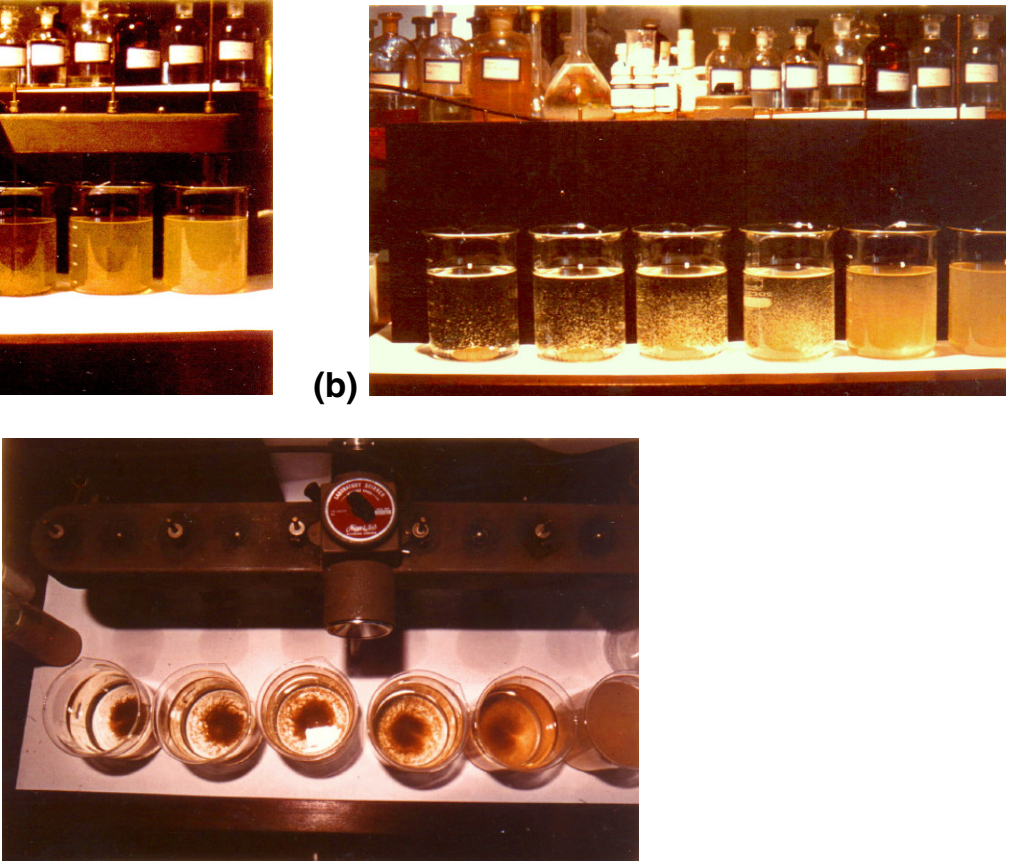

(c)

Fig. 4. The effect of HRC technology on the settleability of agglomerates formed by the POA process from the aggregates formed by the IHDS process at the flocculation optimum with OFA applied at different dosages (purification with ferric chloride, $T u^{R W}=140 \mathrm{NTU}, \bar{G}=100 \mathrm{~s}^{-1}$, agglomeration by SF-A130) - dosages of OFA in beakers from right to left $D=N I L, 0.01 ; 0.03$; $0.05 ; 0.07 ; 0.10 \mathrm{mgl}^{-1}$ : (a) development of agglomerates during POA process, (b) settleability of agglomerates immediately after completion of POA process and removal of stirrers, (c) difference in character of sludge produced.

\section{2, 205-229, 2009}

Optimized conditions for organic flocculant aids in water purification

P. Polasek

Title Page

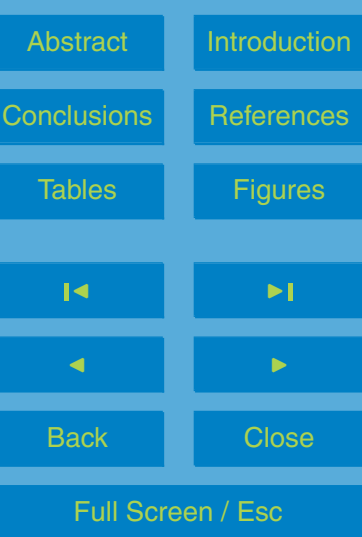

Printer-friendly Version

Interactive Discussion 


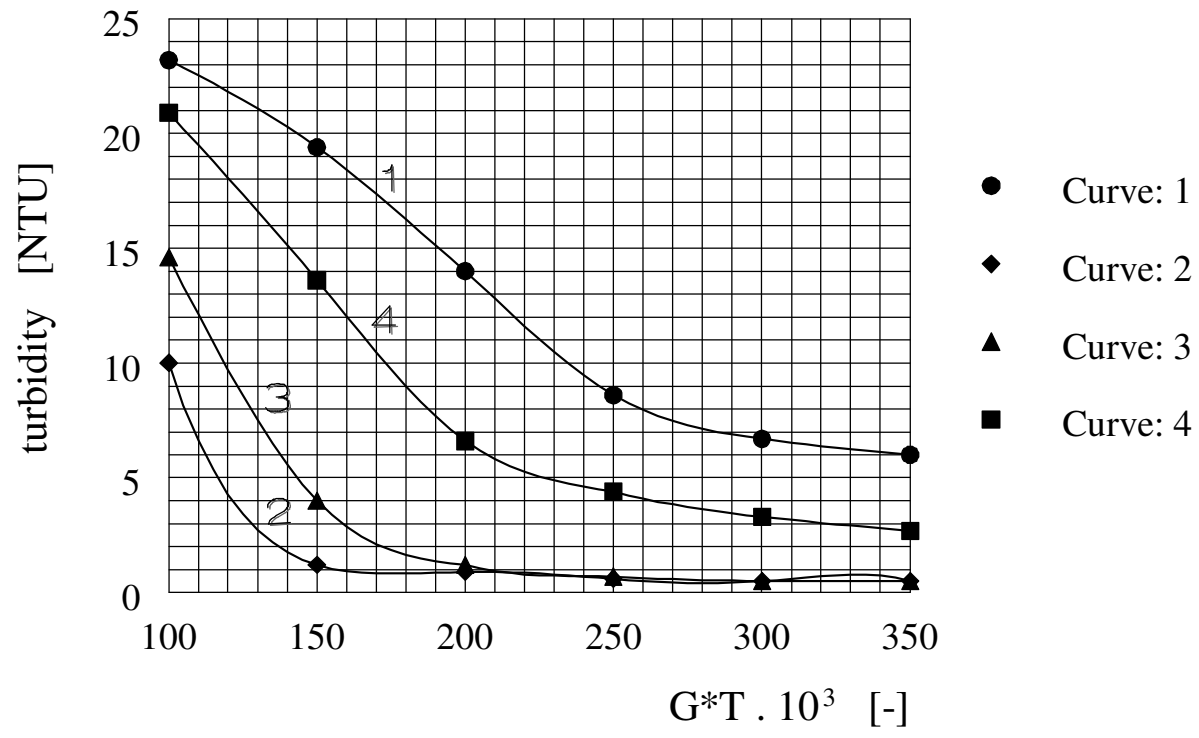

Fig. 5. Influence of sludge recirculation on kinetics of aggregation process. Curve 1: the raw water purified with activated silica $(D=2.0 \mathrm{mg} / \mathrm{l})$ and lime $(D=80 \mathrm{mg} / \mathrm{l})$, curve 2: the raw water was first inoculated with the sediment from the previous test (curve 1) and then purified with activated silica $(D=2.0 \mathrm{mg} / \mathrm{l})$ and lime $(D=80 \mathrm{mg} / \mathrm{l})$, curve 3 : the raw water purified lime $(D=80 \mathrm{mg} / \mathrm{l})$ and the formed suspension agglomerated with OFA under the conditions of the POA process (dosage of SF-A110 D=0.1 mg/l), curve 4: the raw water was first inoculated with the sediment from the previous test (curve 3 ) and then purified lime ( $D=80 \mathrm{mg} / \mathrm{l})$ and the formed suspension agglomerated with OFA under the conditions of the POA process (dosage of SF-A110 D=0.1 mg/l).
2, 205-229, 2009

Optimized conditions for organic flocculant aids in water purification

P. Polasek

\section{Title Page}

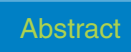

Introduction

Conclusions

References

Tables

Figures

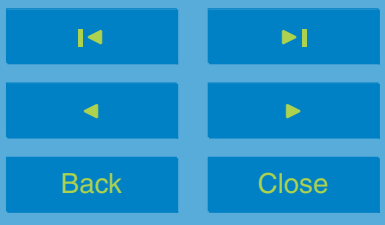

Full Screen / Esc

Printer-friendly Version

Interactive Discussion

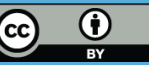

